\title{
Determination of Telomere Length by the Quantitative Fluorescence in Situ Hybridization (Q-FISH) Method
}

\author{
Junko Aida', Naotaka Izumiyama-Shimomura' ${ }^{1}$, Ken-ichi Nakamura1, Naoshi Ishikawa1, \\ Masanori Terai' ${ }^{1}$, Yoko Matsuda' ${ }^{2}$, Shinsuke Aida ${ }^{3}$, Tomio Arai ${ }^{2}$, Kaiyo Takubo' \\ ${ }^{1}$ Research Team for Geriatric Pathology, Tokyo Metropolitan Institute of Gerontology, Tokyo, Japan \\ ${ }^{2}$ Department of Pathology, Tokyo Metropolitan Geriatric Hospital, Tokyo, Japan \\ ${ }^{3}$ Department of Pathology, International University of Health and Welfare Mita Hospital, Tokyo, Japan \\ Email: aidajs@tmig.or.jp
}

Received 19 June 2014; revised 5 August 2014; accepted 22 August 2014

Copyright (C) 2014 by authors and Scientific Research Publishing Inc.

This work is licensed under the Creative Commons Attribution International License (CC BY). http://creativecommons.org/licenses/by/4.0/

cC) (i) Open Access

\begin{abstract}
Telomeres are nucleoprotein complexes located at the ends of eukaryotic chromosomes and are shorten with aging or various causes. Shortened telomere plays an important role for chromosomal instability in carcinogenesis, or a number of diseases in relation to aging. FISH using peptide-nucleic acid (PNA) probe is suitable for analyzing telomeres, because telomere is a part of DNA molecule and localized in chromosomal end in loop shape structure (T-loop). We introduce our telomere analysis for tissue sections and cultured cells in this paper. On the tissue sections, we analyze telomere length with telomere intensity to centromere intensity ratio (TCR), centromere as an inner control. In the cultured cells, we analyze telomere lengths on each chromosome with karyotyping. Those Q-FISH methods by PNA probe are an accurate and reliable tool for research on telomere lengths in various conditions in biology.
\end{abstract}

\section{Keywords}

Telomere, Telomere Length, Q-FISH, Tissue Section, Chromosome

\section{Introduction}

Telomeres are nucleoprotein complexes located at the ends of eukaryotic chromosomes, playing an important role in chromosomal stability by protecting them from end-to-end fusion, degradation, and recombination. In vertebrates, telomeric deoxyribonucleic acid (DNA) sequences consist of tandem TTAGGG repeats, which gen- 
erally shorten by 50 - 200 base pairs with each normal somatic cell division due to incomplete replication of the telomere repeats during DNA synthesis, the so-called "end-replication problem" [1]. We have previously studied telomere shortening with human aging in many organs and tissues using Southern blotting [2] [3]. Telomere shortening is accelerated by various causes, such as exposure to active oxygen [4], alcohol intake [5], sun exposure [6], mental stress [7] and other factors. Telomere shortening results in chromosomal instability, causing fusion or stretching of chromosomal arms, and breakage at late anaphase or telophase, i.e. the breakage-fusionbridge cycle [8], which is a cause of subsequent continuing genetic instability. Therefore, telomere shortening is considered to play an important role in the very early stage of cancerization. Recently, it has also been revealed that telomere shortening is closely related to the incidence of various diseases associated with aging, for example diabetes mellitus [9], dementia [10], myocardial infarction [11], and atherosclerosis [12].

It is also important to investigate telomere length in stem cells, as they have longer telomeres than normal somatic cells due to reprogramming and telomerase expression. Induced pluripotent stem cells (iPSCs) have been reported to have longer telomeres than their parent cells [13]. Telomere measurement would be useful for guaranteeing the quality of iPSCs, because the presence of short telomeres in an iPSC strain would indicate chromosomal instability.

Fluorescence analysis is a highly sensitive and specific analytical tool, and fluorescence in situ hybridization (FISH) using a peptide-nucleic acid (PNA) probe is suitable for analysis of telomeres because the telomere is part of the DNA molecule and localized in a loop-shaped structure (T-loop) at the tip of the chromosome. We have reported a number of studies of telomeres based on human tissue sections and metaphase spreads of cultured cells using quantitative fluorescence in situ hybridization (Q-FISH). Here we introduce our use of telomere analysis for tissue sections and cultured cells.

\section{Q-FISH Methods for Telomere Measurement Using Tissue Sections}

Southern blotting is the gold standard method for measurement of telomere length, and has been used in a range of studies of various cells, tissues, and organs. We have previously determined the annual rates of telomere shortening in a number of different tissues and organs using Southern blotting [2] [3] [14]-[18]. However, unlike cultured cells, tissues are composed of a variety of different cell types, and Southern blotting cannot measure telomere lengths in heterogeneous cell populations, for example in myocardium, which is composed of muscle cells with a few endothelial cells and fibroblasts, hepatic tissue composed of hepatocytes with endothelial cells, fibroblasts and biliary duct cells, and epidermis composed of keratotic cells, granular cells, prickle cells, parabasal cells, and basal cells.

Q-FISH using a fluorescent peptide nucleic acid (PNA) probe on tissue sections can measure the telomere length of each cell type present in a tissue. The PNA probe is an artificially synthesized polymer similar to DNA/ribonucleic acid (RNA) capable of binding to DNA/RNA in a sequence-specific manner. However, in PNA the sugar phosphate backbone has been replaced by a neutral peptide or polyamide backbone, as first synthesized by Nielsen and colleagues [19]. PNAs show highly specific hybridization with DNA/RNA because their neutral peptide backbone is stable and resistant to degradation by DNases, RNases, proteinases and peptidases. Telomere intensity assessed by FISH using a PNA probe is known to correlate with telomere length [20]. Therefore, PNA probes with fluorescence are more sensitive and specific than DNA probes, and are now available in commercial FISH kits.

Q-FISH for tissue sections has a number of advantages over Southern blotting: 1) Each cell or cell group in a tissue section can be analyzed without mixing different cells together, 2) archival tissue can be used instead of fresh tissue, 3) the analysis requires only one or a few paraffin sections, 4) comparison of histologic or immunohistochemical findings on serial slides is possible, and 5) the analysis does not involve the subtelomere. However, the biggest merit is that each cell can be analyzed separately.

There have been many differences among previously reported Q-FISH methods, including the internal controls and probes employed. The approaches used to control for telomere intensity have included: 1) the ratio relative to nuclear intensity, 2) the ratio relative to nuclear or telomeric area, 3) the ratio relative to centromere intensity, 4) comparison against stromal cells (lymphocytes, fibroblasts, or endothelial cells), 5) visual assessment, 6) calibration relative to cultured cells of known telomere length on another slide, and 7) calibration using a block of cultured cells of known telomere length on the same slide.

As fluorochrome staining of nuclei is often influenced by the conditions used for tissue fixation or processing, comparison using approach 1) or 2) would not seem reproducible. "Stromal cells", i.e. lymphocytes, endothe- 
lium and fibroblasts, have relatively constant telomere length in aging than epithelial cells, [21]. However, any method using admixed stromal cells as a control would not be reproducible, and the telomere lengths of stromal cells would be influenced by inflammation or regeneration factors, making them unsuitable as an internal control.

The thickness of the tissue slice used for FISH is 2 - 5 micrometer, which means that most human nuclei, having a larger diameter than the section thickness, would be cut and thus not wholly present in any given section. The relative proportion of centromeres and telomeres within a section would be considered almost the same as that in the entire nuclei because they are distributed uniformly in the nucleus (Figure 1). Also, the length of the centromere is constant among individuals. Therefore, the telomere/centromere ratio can be considered to reflect the telomere length of individual cells. For this reason, we consider that centromere intensity is the best internal control (Figure 2).

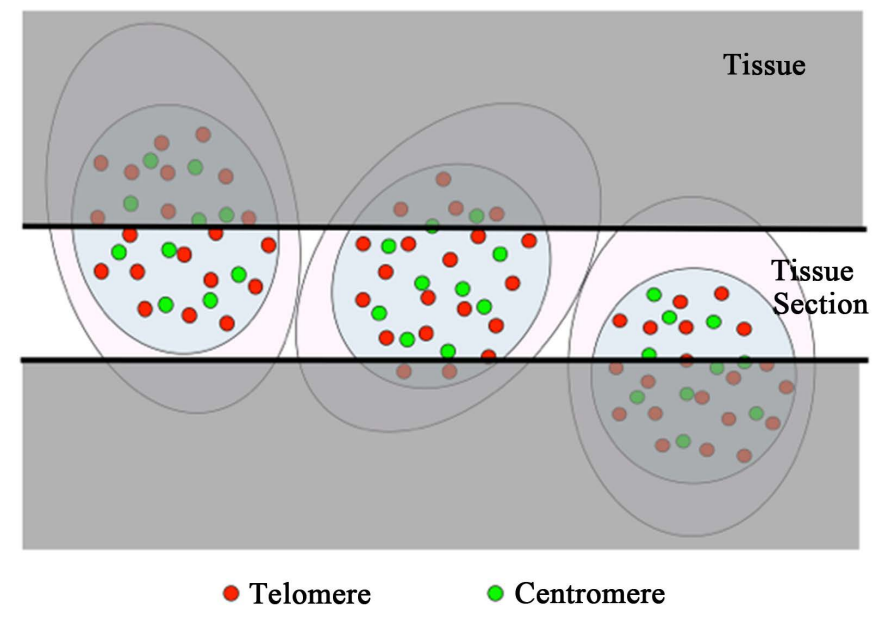

Figure 1. Scheme of our Q-FISH method on tissue sections. The thickness of the tissue slice for Q-FISH is about 2 micrometer. This means that almost all nuclei in human tissue sections are cut, as they are too large to be included entirely within one section. The proportion of centromeres and telomeres within any tissue section is considered to be almost the same as that in the entire cell because they are distributed uniformly in the nucleus.

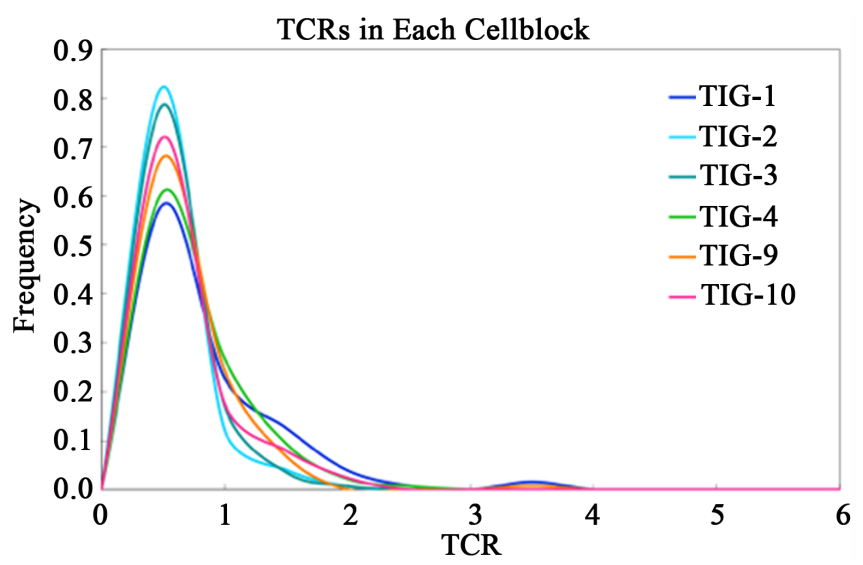

Figure 2. Telomere to Centromere Ratio (TCR) distributions of TIG-1 cell block. In two experiments (TIG-1,2,3,4 and TIG-9,10), TCR distributions of TIG-1 sections from the same cell block showed almost the same figure and peak for TCR. Median values of these TCRs were $0.43,0.22,0.26,0.42,0.36$, and 0.29 (mean: $0.33+0.09$ ). 
Internal control methods 1) to 5) allow researchers to derive only relative, and not actual, telomere lengths. However, methods 6) and 7) allow calculation of actual telomere length from cultured cells of known telomere length as a standard.

We consider that more than 100 cells of each cell type should be subjected to Q-FISH, because the telomere length in each cell of a tissue or culture is distributed over an extremely wide range, as shown by smearing in Southern blotting. However, many studies have assessed only a small number of each cell type.

We used method 3) initially, but have recently used method 7). Details of these methods are described in the next section.

\section{Our Methodology for Q-FISH and Image Analysis for Telomere Measurement}

We have focused on centromeres that are stable under various conditions, and employed FISH along with the telomere to centromere ratio (TCR). We demonstrated different telomere lengths and different annual reduction rates in each group of cells [21]-[23]. In human oral or esophageal carcinoma, shortened telomeres were present in the non-carcinomatous background mucosa showing chromosomal instability (Figure 3) [24]-[26], and shortened telomeres were also present in precancerous lesions such as oral leukoplakia [27] or actinic keratosis of the skin [6]. In various diseases other than cancers, i.e. hepatic cells in biliary atresia [28] or $\beta$ cells in diabetes mellitus (Figure 4) [9], telomere shortening has been demonstrated. In addition, various kinds of telomeric biological changes are evident [5] [29]. Furthermore, we have employed calibration using a cellblock of cultured cells of known telomere length on the same slide, allowing telomere lengths from separate experiments to be compared, and actual telomere lengths of targeted cells to be calculated.
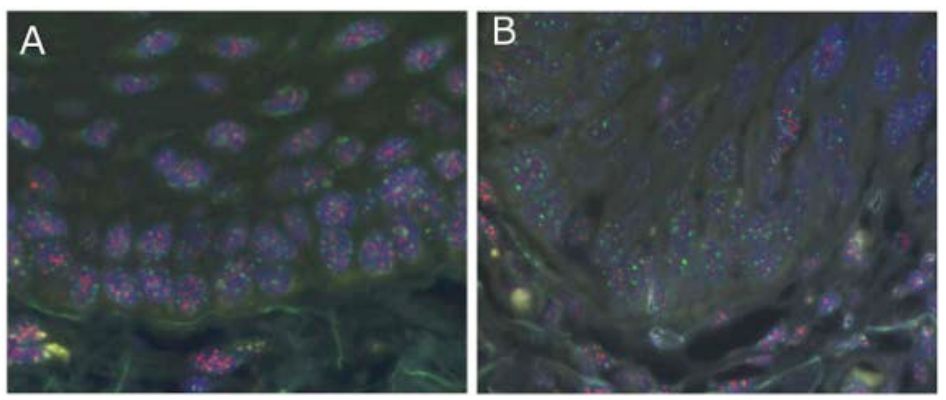

Figure 3. Telomere FISH images of human pancreas. (A) Telomere FISH image of human pancreas (93 y/o female); (B) Telomere FISH with anti-insulin immunofluorescence for the same individual. Inset: Enlarged image. Arrow: anti-insulin-positive cell (beta cell), arrowhead: anti-insulin-negative cell (non-beta cell). Red: telomere signal, green: centromere signal, blue: nuclear DNA, yellow-green: anti-insulin immunofluorescence.
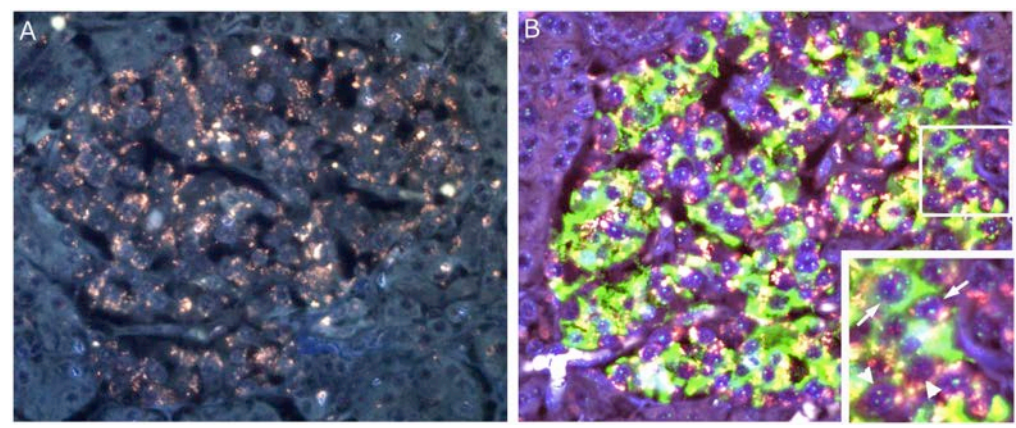

Figure 4. Telomere FISH images of human pancreas. (A) Telomere FISH image of human pancreas (93 y/o female); (B) Telomere FISH with anti-insulin immunofluorescence for the same individual. Inset: Enlarged image. Arrow: anti-insulin-positive cell (beta cell), arrow-head: anti-insulin-negative cell (non-beta cell). Red: telomere signal, green: centromere signal, blue: nuclear DNA, yellow-green: antiinsulin immunofluorescence. 


\subsection{Tissue Processing}

Tissues were fixed for $5 \mathrm{~h}$ in $10 \%$ buffered formalin and then subjected to standard tissue processing and paraffin embedding. They were then sliced into Sections 3 micrometer thick for histological and immunohistochemical examinations.

\subsection{Telomere Fluorescence Analysis on Tissue Section}

After the samples had been embedded in paraffin and cut into $2-\mu \mathrm{m}$ sections, the slides were immersed in O-xylene for $7 \mathrm{~min}$ at room temperature (RT), dipped in 100\% ethanol, and air-dried. They were then dipped in $0.2 \mathrm{~mol} / \mathrm{L} \mathrm{HCl}$ for $20 \mathrm{~min}$ at RT, followed by rinsing in distilled water for $10 \mathrm{~min}$ at RT, incubation in $1 \mathrm{~mol} / \mathrm{L}$ $\mathrm{NaSCN}$ for $30 \mathrm{~min}$ at $80^{\circ} \mathrm{C}$, and rinsing again in water. The slides were then incubated in pepsin $(1 \mathrm{mg} / \mathrm{mL}$ acid $\mathrm{H}_{2} \mathrm{O}$ ) for $15 \mathrm{~min}$ at $37^{\circ} \mathrm{C}$, rinsed in water, dipped in $100 \%$ ethanol, and air-dried. The slides were then treated with $0.5 \mathrm{mg} / \mathrm{mL}$ ribonuclease A for $10 \mathrm{~min}$ at $37^{\circ} \mathrm{C}$, rinsed with phosphate-buffered saline, dehydrated through an ethanol series $(70 \%, 90 \%, 100 \%)$, and dried.

We hybridized the tissue sections with $30 \mathrm{microgram} / \mathrm{ml}$ (6.04 micromol/L) PNA telomere probe (telo C Cy3 probe: 5'-CCCTAACCCTAACCCTAA-3'V; Fasmac, Atsugi City, Kanagawa, Japan) conjugated to Cy3 (final concentration 1.5 microgram $/ \mathrm{ml} ; 0.30 \mathrm{micromol} / \mathrm{L}$ ) and the PNA centromere probe (Cenp1 probe:

5'-CTTCGTTGGAAACGGGGT-3'; Fasmac) conjugated to fluorescein isothiocyanate (FITC; final concentration $0.6 \mathrm{microgram} / \mathrm{ml} ; 0.12 \mathrm{micromol} / \mathrm{L}$ ) for $3 \mathrm{~min}$ at $80^{\circ} \mathrm{C}$, and the slides were incubated for $1 \mathrm{~h}$ at $\mathrm{RT}$. We then washed the slides four times in $70 \%$ formamide buffer for 15 min each time, followed by four washes in TBST $(0.1 \mathrm{~mol} / \mathrm{L}$ Tris, $0.15 \mathrm{~mol} / \mathrm{L} \mathrm{NaCl}, 0.08 \%$ Tween 20$)$ for 5 min each time. Finally, the slides were dehydrated through an ethanol series and air-dried. The nuclei were then stained with 4',6-diamidino-2-phenylindole dihydrochloride (DAPI; Molecular Probes, Eugene, OR, USA) and the slides were mounted with Vectashield (Vector Laboratories, Burlingame, CA, USA).

\subsection{Q-FISH and Image Analysis of Telomeres}

Q-FISH digital images were captured by a charge-coupled device camera (RETIGA-2000DC, QIMAGING, Surrey, BC, Canada) mounted on an epifluorescence microscope (80i; Nikon, Tokyo, Japan) equipped with a triple band-pass filter set for DAPI/ FITC/Cy3 (part 61010, Chroma Technology, Rockingham, VT, USA) with an objective lens (Plan Fluor 40/0.75, Nikon). Microscope control and image acquisition were carried out using the Image-Pro Plus software package (version 5.0, Media Cybernetics, Silver Spring, MD, USA). The captured images were analyzed using our own original tissue analysis software package, Tissue Telo ver.3.1, which allows manual identification of nuclear regions from the composite color image: DAPI, blue channel; FITC, green; $\mathrm{Cy} 3$, red. Telomere and centromere signals were then determined as pixels showing the brightest intensities (top $5 \%$ ) within each selected nuclear region. The measured signal intensities were corrected for background autofluorescence as determined from the mean of the pixels showing the lowest intensities (lowest 20\%). The top 5\% and lowest $20 \%$ thresholds had previously been shown to give consistent results [30]. Because there is no guarantee that the entire nucleus is captured within a tissue section, the total corrected telomere signal (integrated optical density) for each nucleus is further normalized by the corresponding integrated optical density of the centromere [22]. We have previously verified in a fluorescence flow study that the mean optical density of our centromere probe was constant among human blood cells from individuals of various age groups and cultured fibroblasts (TIG-1, 3 population doubling levels). In summary, our cell-normalized telomere length estimate for each nucleus is defined as the ratio of the detected telomere signal intensity to the centromere signal intensity (TCR). TCRs obtained from 100 to 300 cells were analyzed.

\subsection{Q-FISH with Immunofluorescence Superimposition for Identifying Target Cells}

When target cells are difficult to distinguish from other cells because of their similar appearance on FISH slides, or intermingled with other cells in the tissue, superimposition of immunofluorescence staining is useful [9] [31]. However, two important points should be borne in mind: 1) The immunofluorescence antigen is present outside the nucleus, and 2) fluorochrome conjugated to secondary antibody should have a fluorescence wavelength peak for absorbance and emission sufficiently distinct from the fluorochrome for recognition of the telomere and centromere. If the fluorochrome used for immunofluorescence staining overlaps the fluorescence signals of the telomere and centromere, the intensity of the telomere and/or centromere signal cannot be analyzed correctly, and 
the telomere length cannot be estimated accurately.

For example, pancreatic $\alpha$ cells and $\beta$ cells have been distinguished using a guinea pig anti-insulin antibody (No. N1542, Dako, Glostrup, Denmark), a guinea pig anti-glucagon antibody (No. M182, Takara Bio Inc., Shiga, Japan), and a secondary goat anti-guinea pig antibody labeled with Cy-5 (absorbance max/emission max = 649/ $670 \mathrm{~nm}$, ab6567, Abcamplc, Cambridge, UK) after FISH [9]. The fluorochromes we have used for telomere FISH are Cy3: absorbance/emission $\max =550 / 570 \mathrm{~nm}$, and FITC: 494/521 nm.

Superimposition of immunofluorescence staining was continued to ordinary FISH course. Slides were processed for indirect immunofluorescence by rinsing them in PBST followed by application of the primary antibody and incubation overnight at $4^{\circ} \mathrm{C}$. The slides were then rinsed in PBST followed by application of a fluorescent secondary antibody labeled with another fluorochrome, and incubated at room temperature for $30 \mathrm{~min}$. They were then rinsed in PBST, and thoroughly rinsed in deionized water, followed by draining and staining with DAPI. The slides were then rinsed well in deionized water, drained, mounted with Prolong anti-fade mounting medium, coverslipped, and imaged or stored at $-20^{\circ} \mathrm{C}$ until used.

\subsection{Normalization of TCR Using a Cell Block}

As a control for variations in sample preparation, we also carried out Q-FISH on a cell block-section of a cultured cell strain, TIG-1 [32], that had been subcultured (34 PDL; population doubling level) and had a telomere length of $8.6 \mathrm{kbp}$ as measured by Southern blot analysis. This was placed on the same slide as the tissue sections. Every TCR for the cells was divided by the mean TCR for the cell block to give the NTCR [21].

\section{Q-FISH Method for Telomeres on Chromosomes}

The stage of critical telomere shortening has been correlated with the occurrence of many dicentric chromosomes caused by fusions [33]. Dicentric chromosomes are very unstable, and therefore it is considered that formation of such chromosomes by critical telomere shortening is an initial step of telomere-dependent chromosomal and genomic instability, and involved in the initial stage of cancerization. Chromosomal abnormalities such as trisomy, monosomy or aneuploidy can cause serious illnesses or syndromes. These facts suggest that the chromosome or chromosomes affected by instability carry specific causative genes. Although Giemsa staining is the standard method for karyotype analysis, FISH images can also be used for this purpose along with DAPI staining. Therefore, analysis of the telomere length of each chromosome seems important for clarifying the mechanisms of disease.

\section{Our Methodology for Q-FISH and Image Analysis of Telomeres on Chromosomes}

We have reported telomere analysis of various cell types using our own methodology. For Q-FISH of normal fibroblast strains, we demonstrated that chromosomes having excessively shortened telomeres at late PDLs showed features of chromosomal instability such as fusions and anaphase bridges [34]. When examining telomeres of peripheral blood lymphocytes, we also observed that the telomeres of trisomic chromosomes were neither shorter nor longer than the mean telomere length of chromosomes as a whole among subjects with trisomies 18 and 21 (intra-cell comparison), and we were unable to conclude that there were differences in telomere length between 18 trisomy and diploid subjects, or between 21 trisomy and diploid subjects (inter-individual comparison) [35].

In our study of iPSCs, we demonstrated that the median telomere length of iPSCs usually exceeded that of the parental cells, although some iPSCs showed aneuploidy on karyotype analysis, and their telomeres shortened as the number of passages increased [13].

\subsection{Sample Processing}

Cultured cells were trypsinized, plated at near-confluency, and incubated with colcemid for $12 \mathrm{~h}$ before cell harvest. They were than treated with hypotonic $75 \mathrm{mmol} \mathrm{KCl}$ solution for $30-60 \mathrm{~min}$ at $37^{\circ} \mathrm{C}$. Finally they were fixed in methanol-acetic acid (1:3) and dropped on clean slides and/or stored at $-20^{\circ} \mathrm{C}$ in fixative.

\subsection{Telomere Fluorescence Analysis on Chromosomes}

Analysis of the fluorescence images was performed as described previously [36]. For karyotype analysis and 
quantitative analysis of telomeres, the metaphase chromosomes were fixed and then hybridized using the PNA-FISH preparation method described previously [37].

The telomere hybridization method for chromosomes is almost the same as that for tissue sections. We hybridized the slides with $30 \mu \mathrm{g} / \mathrm{ml}(6.04 \mathrm{micromol} / \mathrm{L})$ PNA telomere probe (telo C Cy3 probe:

5'-CCCTAACCCTAACCCTAA-3'V; Fasmac, Atsugi City, Kanagawa, Japan) conjugated to Cy3 (final concentration $1.5 \mathrm{microgram} / \mathrm{ml} ; 0.30 \mathrm{mmol} / \mathrm{L}$ ) and the PNA centromere probe (Cenp1 probe:

5'-CTTCGTTGGAAACGGGGT-3'; Fasmac) conjugated to fluorescein isothiocyanate (FITC; final concentration $0.6 \mu \mathrm{g} / \mathrm{ml} ; 0.12 \mathrm{mmol} / \mathrm{L}$ ) for $3 \mathrm{~min}$ at $80^{\circ} \mathrm{C}$, and then the slides were incubated for $1 \mathrm{~h}$ at RT. We then washed the slides four times in 70\% formamide buffer for 15 min each time, followed by four washes in TBST $(0.1 \mathrm{~mol} / \mathrm{L}$ Tris, $0.15 \mathrm{~mol} / \mathrm{L} \mathrm{NaCl})$ for $5 \mathrm{~min}$ each time. Finally, the slides were dehydrated through an ethanol series and air-dried. The nuclei were then stained with DAPI (Molecular Probes, Eugene, OR, USA) and the slides were mounted with Vectashield (Vector Laboratories, Burlingame, CA, USA) (Figure 5).

\subsection{Q-FISH and Image Analysis}

Digital images were recorded with a CCD camera, Axio Cam MRm (Zeiss, Oberkochen, Germany), mounted on an Axio Imager MAT (Zeiss) epifluorescence microscope equipped with a triple band-pass filter for Cy3/FITC/ DAPI (61010 Chroma Technology, Corp., Rockingham, VT, USA) and a 63× oil-objective lens (Zeiss EC PlanNEOFLUAR $63 \times / 1.241 \infty / 0.17$ ). Microscope control and image acquisition were performed with the Image-Pro Plus software package version 5.0 (Media Cybernetics Co. Ltd., MD, USA). Two levels of calibration were used to ensure a reliable quantitative estimation of telomere length in the various samples. First, to correct for daily variations in lamp intensity and alignment, images of fluorescent beads (orange beads, size $0.2 \mathrm{~mm}$, Molecular Probes Inc.) were acquired just prior to acquisition of the images from the samples. The fluorescence intensities of the beads and telomeres were analyzed with the TFLTelo-V2 software package (Terry Fox Laboratory, BC Cancer Research Centre, Canada). Second, relative telomere fluorescence units (TFUs) were extrapolated from and correlated with the Southern blot data for the TIG-1 strain (12, 32, 60, and 62 PDLs). For TIG-1, a linear relationship was determined between TRF length and the measured intensity of the telo C probe.

\subsection{Telomere Length Measurements of Individual Arms in Metaphase Spreads}

Using the ISIS karyotyping system (MetaSystems, Altlussheim, Germany), we analyzed the karyotypes of 10 20 metaphase spreads on slides with FISH from each cell strain or line. We then measured the telomere fluorescence intensities of the p- and q-arms of all the chromosomes in the metaphase spread individually.

\section{Conclusion}

We have demonstrated that use of the TCR is reliable for estimation of telomere length in different cell types of tissue section. Also, analysis of the telomeres of individual chromosome is able to clarify the changes in telomere length occurring in various cells or conditions. Therefore, the Q-FISH method using a PNA probe gives
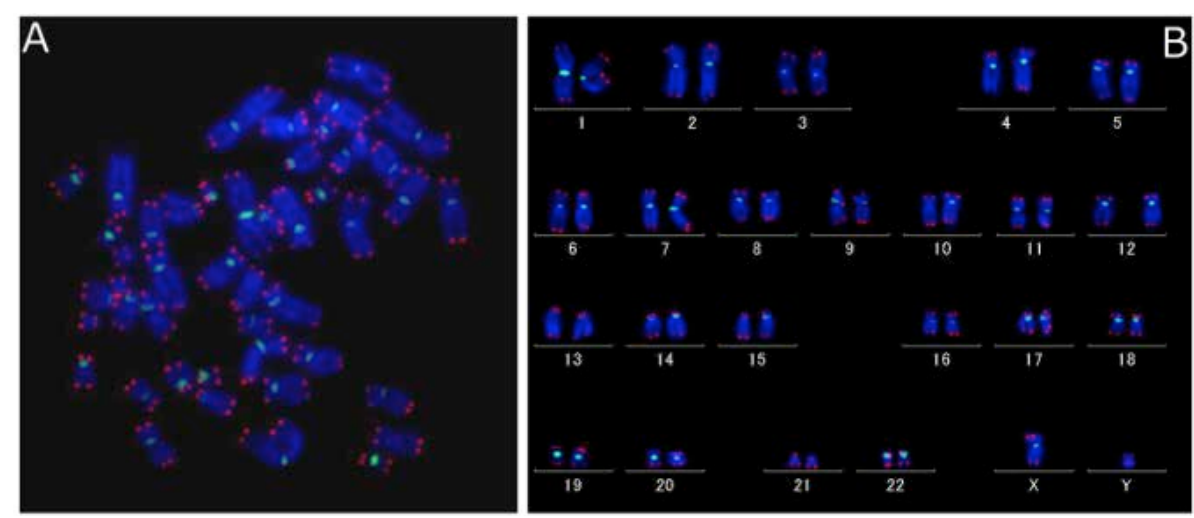

Figure 5. Telomere FISH image of TIG-1 cultured cells in metaphase (A) and with karyotyping (B). Red: telomere signal, green: centromere signal, blue: nuclear DNA. 
outstanding results for telomere analysis of either sections or chromosomes in terms of accuracy and reproducibility, and is useful for research on telomere length dynamics in various biological conditions.

\section{References}

[1] Levy, M.Z., Allsopp, R.C., Futcher, A.B., Greider, C.W. and Harley, C.B. (1992) Telomere End-Replication Problem and Cell Aging. Journal of Molecular Biology, 225, 951-960. http://dx.doi.org/10.1016/0022-2836(92)90096-3

[2] Takubo, K., Izumiyama-Shimomura, N., Honma, N., Sawabe, M., Arai, T., et al. (2002) Telomere Lengths are Characteristic in Each Human Individual. Experimental Gerontology, 37, 523-531. http://dx.doi.org/10.1016/S0531-5565(01)00218-2

[3] Nakamura, K., Izumiyama-Shimomura, N., Sawabe, M., Arai, T., Aoyagi, Y., et al. (2002) Comparative Analysis of Telomere Lengths and Erosion with Age in Human Epidermis and Lingual Epithelium. Journal of Investigative Dermatology, 119, 1014-1019. http://dx.doi.org/10.1046/j.1523-1747.2002.19523.x

[4] von Zglinicki, T. (2002) Oxidative Stress Shortens Telomeres. Trends in Biochemical Sciences, 27, 339-344. http://dx.doi.org/10.1016/S0968-0004(02)02110-2

[5] Aida, J., Yokoyama, A., Izumiyama, N., Nakamura, K., Ishikawa, N., et al. (2011) Alcoholics Show Reduced Telomere Length in the Oesophagus. The Journal of Pathology, 223, 410-416. http://dx.doi.org/10.1002/path.2817

[6] Ikeda, H., Aida, J., Hatamochi, A., Hamasaki, Y., Izumiyama-Shimomura, N., et al. (2014) Quantitative Fluorescence in Situ Hybridization Measurement of Telomere Length in Skin with/without Sun Exposure or Actinic Keratosis. Human Pathology, 45, 473-480. http://dx.doi.org/10.1016/j.humpath.2013.10.009

[7] Epel, E.S., Blackburn, E.H., Lin, J., Dhabhar, F.S., Adler, N.E., et al. (2004) Accelerated Telomere Shortening in Response to Life Stress. Proceedings of the National Academy of Sciences of the USA, 101, 17312-17315. http://dx.doi.org/10.1073/pnas.0407162101

[8] McClintock, B. (1951) Chromosome Organization and Genic Expression. Cold Spring Harbor Symposia on Quantitative Biology, 16, 13-47. http://dx.doi.org/10.1101/SQB.1951.016.01.004

[9] Tamura, Y., Izumiyama-Shimomura, N., Kimbara, Y., Nakamura, K.I., Ishikawa, N., et al. (2014) Beta Cell Telomere Attrition in Diabetes: Inverse Correlation between HbA1c and Telomere Length. The Journal of Clinical Endocrinology Metabolism.

http://press.endocrine.org/doi/abs/10.1210/jc.2014-1222?url_ver=Z39.88-2003\&rfr_id=ori:rid:crossref.org\&rfr_dat=cr _pub\%3dpubmed

[10] von Zglinicki, T., Serra, V., Lorenz, M., Saretzki, G., Lenzen-Grossimlighaus, R., et al. (2000) Short Telomeres in Patients with Vascular Dementia: an Indicator of Low Antioxidative Capacity and a Possible Risk Factor? Laboratory Investigation, 80, 1739-1747. http://dx.doi.org/10.1038/labinvest.3780184

[11] Maubaret, C.G., Salpea, K.D., Jain, A., Cooper, J.A., Hamsten, A., et al. (2010) Telomeres Are Shorter in Myocardial Infarction Patients Compared to Healthy Subjects: Correlation with Environmental Risk Factors. Journal of Molecular Medicine, 88, 785-794. http://dx.doi.org/10.1007/s00109-010-0624-3

[12] Chang E. and Harley, C.B. (1995) Telomere Length and Replicative Aging in Human Vascular Tissues. Proceedings of the National Academy of Sciences of the United States of America, 92, 11190-11194. http://dx.doi.org/10.1073/pnas.92.24.11190

[13] Terai, M., Izumiyama-Shimomura, N., Aida, J., Ishikawa, N., Kuroiwa, M., et al. (2013) Investigation of Telomere Length Dynamics in Induced Pluripotent Stem Cells Using Quantitative Fluorescence in Situ Hybridization. Tissue and Cell, 45, 407-413. http://dx.doi.org/10.1016/j.tice.2013.07.003

[14] Takubo, K., Nakamura, K., Izumiyama, N., Sawabe, M., Arai, T., et al. (1999) Telomere Shortening with Aging in Human Esophageal Mucosa. Age, 22, 95-99. http://dx.doi.org/10.1007/s11357-999-0011-6

[15] Takubo, K., Nakamura, K., Izumiyama, N., Furugori, E., Sawabe, M., et al. (2000) Telomere Shortening with Aging in Human Liver. The Journals of Gerontology Series A: Biological Sciences and Medical Sciences, 55, B533-B536. http://dx.doi.org/10.1093/gerona/55.11.B533

[16] Ishii, A., Nakamura, K., Kishimoto, H., Honma, N., Aida, J., et al. (2006) Telomere Shortening with Aging in the Human Pancreas. Experimental Gerontology, 41, 882-886. http://dx.doi.org/10.1016/j.exger.2006.06.036

[17] Nakamura, K., Takubo, K., Izumiyama-Shimomura, N., Sawabe, M., Arai, T., et al. (2007) Telomeric DNA Length in Cerebral Gray and White Matter Is Associated with Longevity in Individuals Aged 70 Years or Older. Experimental Gerontology, 42, 944-950. http://dx.doi.org/10.1016/j.exger.2007.05.003

[18] Ishikawa, N., Nakamura, K., Izumiyama, N., Aida, J., Sawabe, M., et al. (2012) Telomere Length Dynamics in the Human Pituitary Gland: Robust Preservation throughout Adult Life to Centenarian Age. Age, 34, 795-804. http://dx.doi.org/10.1007/s11357-011-9280-y 
[19] Nielsen, P.E., Egholm, M., Berg, R.H. and Buchardt, O. (1991) Sequence-Selective Recognition of DNA by Strand Displacement with a Thymine-Substituted Polyamide. Science, 254, 1497-1500.

http://dx.doi.org/10.1126/science.1962210

[20] Lansdorp, P.M., Verwoerd, N.P., van de Rijke, F.M., Dragowska, V., Little, M.T., et al. (1996) Heterogeneity in Telomere Length of Human Chromosomes. Human Molecular Genetics, 5, 685-691. http://dx.doi.org/10.1093/hmg/5.5.685

[21] Aida, J., Izumiyama-Shimomura, N., Nakamura, K., Ishikawa, N., Poon, S.S., et al. (2008) Basal Cells Have Longest Telomeres Measured by Tissue Q-FISH Method in Lingual Epithelium. Experimental Gerontology, 43, 833-839. http://dx.doi.org/10.1016/j.exger.2008.06.001

[22] Aida, J., Izumiyama-Shimomura, N., Nakamura, K., Ishii, A., Ishikawa, N., et al. (2007) Telomere Length Variations in 6 Mucosal Cell Types of Gastric Tissue Observed Using a Novel Quantitative Fluorescence in Situ Hybridization Method. Human Pathology, 38, 1192-1200. http://dx.doi.org/10.1016/j.humpath.2006.11.023

[23] Kurabayashi, R., Takubo, K., Aida, J., Honma, N., Poon, S.S., et al. (2008) Luminal and Cancer Cells in the Breast Show More Rapid Telomere Shortening than Myoepithelial Cells and Fibroblasts. Human Pathology, 39, 1647-1655. http://dx.doi.org/10.1016/j.humpath.2008.04.005

[24] Aida, J., Izumo, T., Shimomura, N., Nakamura, K.I., Ishikawa, N., et al. (2010) Telomere Lengths in the Oral Epithelia with and without Carcinoma. European Journal of Cancer, 46, 430-438. http://dx.doi.org/10.1016/j.ejca.2009.10.018

[25] Takubo, K., Fujita, M., Izumiyama, N., Nakamura, K., Ishikawa, N., et al. (2010) Q-FISH Analysis of Telomere and Chromosome Instability in the Oesophagus with and without Squamous Cell Carcinoma in Situ. Journal of Pathology, 221, 201-209. http://dx.doi.org/10.1002/path.2704

[26] Shiraishi, H., Mikami, T., Aida, J., Nakamura, K., Izumiyama-Shimomura, N., et al. (2009) Telomere Shortening in Barrett's Mucosa and Esophageal Adenocarcinoma and Its Association with Loss of Heterozygosity. Scandinavian Journal of Gastroenterology, 44, 538-544. http://dx.doi.org/10.1080/00365520902718705

[27] Aida, J., Kobayashi, T., Saku, T., Yamaguchi, M., Shimomura, N., et al. (2012) Short Telomeres in an Oral Precancerous Lesion: Q-FISH Analysis of Leukoplakia. Journal of Oral Pathology Medicine, 41, 372-378. http://dx.doi.org/10.1111/j.1600-0714.2011.01120.X

[28] Sanada, Y., Aida, J., Kawano, Y., Nakamura, K., Shimomura, N., et al. (2012) Hepatocellular Telomere Length in Biliary Atresia Measured by Q-FISH. World Journal of Surgery, 36, 908-916. http://dx.doi.org/10.1007/s00268-012-1453-Z

[29] Aida, J., Yokoyama, A., Shimomura, N., Nakamura, K., Ishikawa, N., et al. (2013) Telomere Shortening in the Esophagus of Japanese Alcoholics: Relationships with Chromoendoscopic Findings, ALDH2 and ADH1B Genotypes and Smoking History. Public Library of Science One, 8, e63860.

[30] O’Sullivan, J.N., Finley, J.C., Risques, R.A., Shen, W.T., Gollahon, K.A., et al. (2004) Telomere Length Assessment in Tissue Sections by Quantitative FISH: Image Analysis Algorithms. Cytometry A, 58, 120-131. http://dx.doi.org/10.1002/cyto.a.20006

[31] Meeker, A.K., Gage, W.R., Hicks, J.L., Simon, I., Coffman, J.R., et al. (2002) Telomere Length Assessment in Human Archival Tissues: Combined Telomere Fluorescence in Situ Hybridization and Immunostaining. American Journal of Pathology, 160, 1259-1268. http://dx.doi.org/10.1016/S0002-9440(10)62553-9

[32] Ohashi, M., Aizawa, S., Ooka, H., Ohsawa, T., Kaji, K., et al. (1980) A New Human Diploid Cell Strain, TIG-1, for the Research on Cellular Aging. Experimental Gerontology, 15, 121-133. http://dx.doi.org/10.1016/0531-5565(80)90083-2

[33] Mathieu, N., Pirzio, L., Freulet-Marriere, M.A., Desmaze, C. and Sabatier, L. (2004) Telomeres and Chromosomal Instability. Cellular and Molecular Life Sciences, 61, 641-656. http://dx.doi.org/10.1007/s00018-003-3296-0

[34] Takubo, K., Aida, J., Izumiyama, N., Ishikawa, N., Fujiwara, M., et al. (2010) Chromosomal Instability and Telomere Lengths of Each Chromosomal Arm Measured by Q-FISH in Human Fibroblast Strains Prior to Replicative Senescence. Mechanisms of Ageing and Development, 131, 614-624. http://dx.doi.org/10.1016/j.mad.2010.08.007

[35] Nakamura, K., Ishikawa, N., Izumiyama, N., Aida, J., Kuroiwa, M., et al. (2014) Telomere Lengths at Birth in Trisomies 18 and 21 Measured by Q-FISH. Gene, 533, 199-207. http://dx.doi.org/10.1016/j.gene.2013.09.086

[36] Kammori, M., Izumiyama, N., Nakamura, K.I., Kurabayashi, R., Kashio, M., et al. (2006) Telomere Metabolism and Diagnostic Demonstration of Telomere Measurement in the Human Esophagus for Distinguishing Benign from Malignant Tissue by Tissue Quantitative Fluorescence in Situ Hybridization. Oncology, 71, 430-436. http://dx.doi.org/10.1159/000108612

[37] Poon, S.S. and Lansdorp, P.M. (2001) Quantitative Fluorescence in Situ Hybridization (Q-FISH). Current Protocols in Cell Biology. http://onlinelibrary.wiley.com/doi/10.1002/0471143030.cb1804s12/abstract 
Scientific Research Publishing (SCIRP) is one of the largest Open Access journal publishers. It is currently publishing more than 200 open access, online, peer-reviewed journals covering a wide range of academic disciplines. SCIRP serves the worldwide academic communities and contributes to the progress and application of science with its publication.

Other selected journals from SCIRP are listed as below. Submit your manuscript to us via either submit@scirp.org or Online Submission Portal.
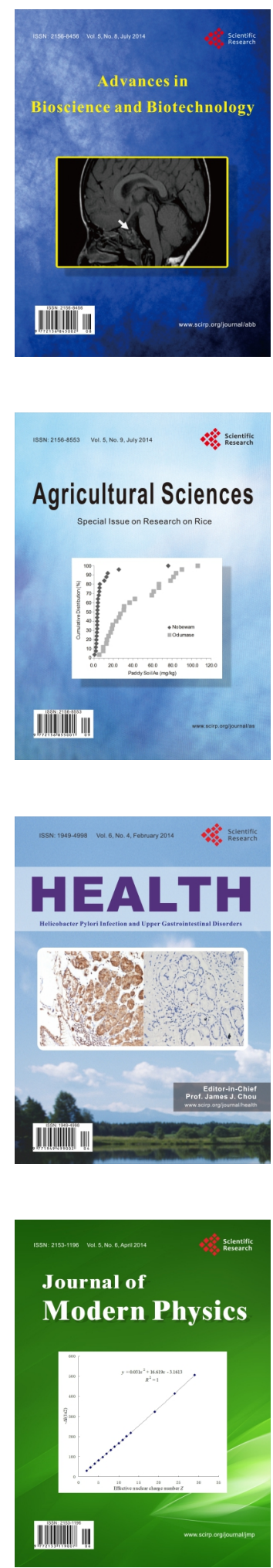
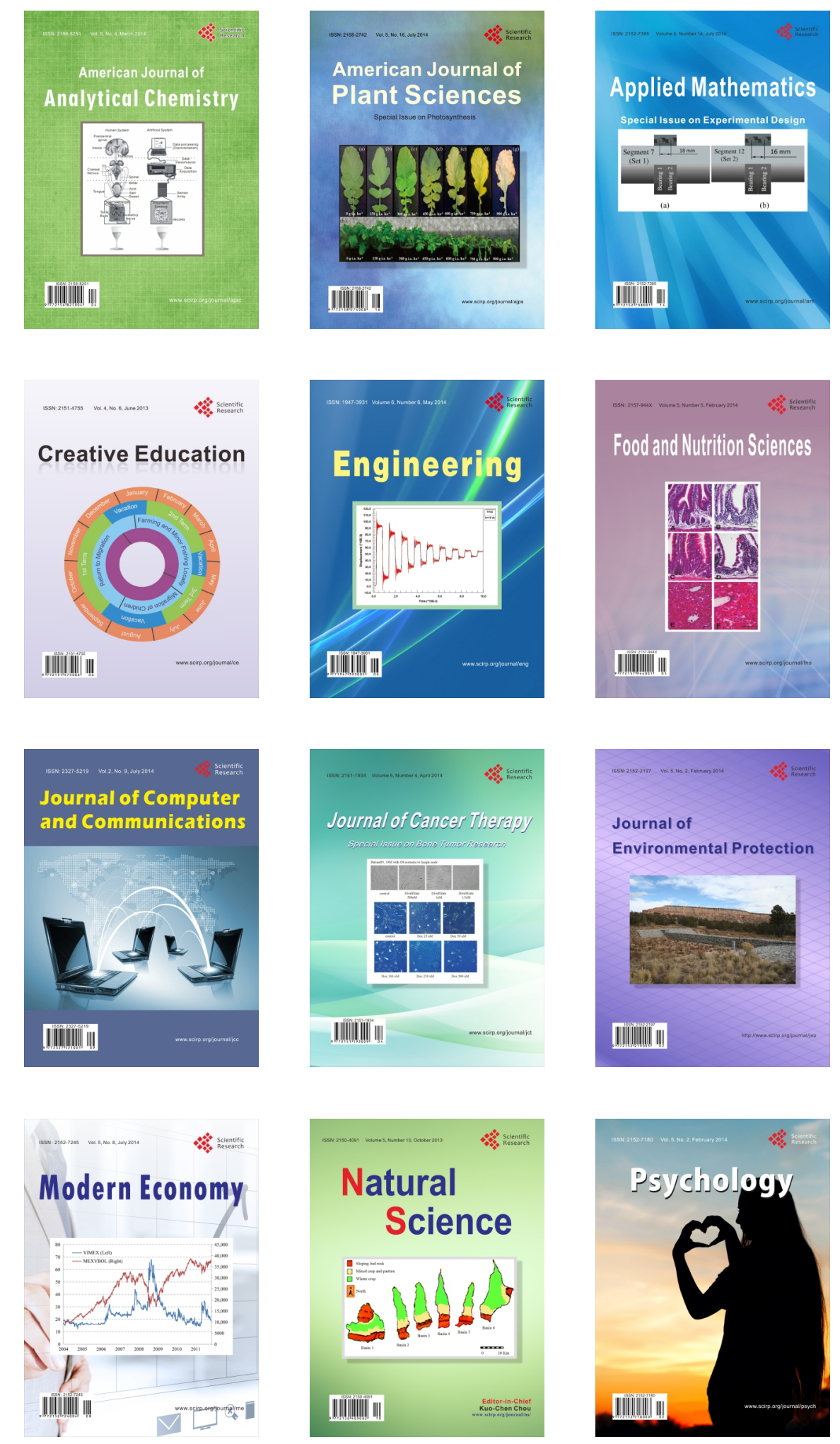